\title{
Highly Efficient Dye-Sensitized Solar Cells based on Carbon Nanofibers Counter Electrodes
}

\author{
Ming-Kun WANG ${ }^{1, a}$, Jun $X U^{2, b}$, Ya-Bing SUN ${ }^{3, c}$, Hui-Ying WANG ${ }^{3}$, Ti-Ti XIE ${ }^{3}$, \\ Rui-Xue CHEN ${ }^{1}$, Ling $\mathrm{LI}^{1^{*}}$, Miao ZHANG ${ }^{3^{*}}$ and Xiao-Xian YUAN ${ }^{1^{*}}$ \\ ${ }^{1}$ Heibei Key Laboratory of Optic-electronic Information Materials, College of Physics Science and \\ Technology, Heibei Unversity, Baoding 071002, China \\ ${ }^{2}$ Huizhou College of Business, Huizhou, 056025, China \\ ${ }^{3}$ College of Chemistry and Environmental Science, Hebei University, Baoding 071002, China \\ a wmk_1234@126.com, bujun0830@163.com , 'c18731225892@163.com
}

Keywords: Carbon nanofiber, Counter electrode, Solar Cell, Film thickness.

Abstract. Carbon nanofibers (CNFs) exhibiting a large surface area and structural stability can provide high electrochemical performance in dye-sensitized solar cells (DSSCs). The effect of CNFs layer thickness on the performance of the DSSCs was researched by cyclic voltammetry (CV), and Tafel polarization measurements. The highest power-conversion efficiency (PCE) of 6.07\% was achieved for the DSSC fabricated with CNFs CE at the optimized film thickness of $13 \mu \mathrm{m}$, a value similiar to that achieved with Pt CE (6.2\%).

\section{Introduction}

Dye-sensitized solar cells (DSSCs) have gained intense attention as one of hopeful substitute to traditional silicon-based cells ever since Grätzel's group first introduced it, because of their remarkable plasticity, low-cost, simple fabrication process, environmental friendliness, and relatively high power conversion efficiency [1, 2]. To date, based on new type cobalt electrolyte, the highest power-conversion efficiency (PCE) of DSSCs have reached 13\%, achieved in Grätzel's group [3]. A typical DSSC is constructed with a dye-sensitized thin film of $\mathrm{TiO}_{2}$ as the photoanode, an electrolyte and a counter electrode (CE) $[4,5]$. Although the platinum (Pt) is the most popularly selected as counter electrode in DSSCs due to its excellent electrocatalytic activity, superior electrical conductivity, efficient electron transport and high stability, Pt is high cost (one of the most expensive materials available) and easily corroded in the electrolyte solution hinder its widespread application [6-10]. Therefore, it is required to explore cost-effective functional electrode materials with high catalytic activity to be utilized as Pt alternatives for DSSCs counter electrodes.

Heretofore, several kinds of carbonaceous materials, such as carbon black, graphite, carbon nanotubes, and activated carbon, have been investigated as substitutes for expensive Pt [11-14]. Murakami et al. found that the PCE of DSSCs was greatly impact on the thickness of the carbon layer [15]. Carbon nanofibers (CNFs) are versatile material exhibiting excellent conductivities for electricity and heat, structural stability and immense specific surface area, which has been applied widely in electrochemical energy devices [16].

In view of these facts mentioned above, optimization of the performance of DSSCs based on cobalt electrolyte and CNFs with different thicknesses were performed, including a study of the electrochemical catalytic activity, with the purpose of exploring the effects of CNFs film thickness on the performance of the DSSCs. It is notable revealing that the thickness of $13 \mu \mathrm{m}$ was sufficient to achieve a high-performance CNFs CE. 


\section{Experimental Studies}

\section{Sample Preparation}

Polyacrylonitrile (PAN, $2 \mathrm{~g}$ ) was dissolved in DMF (18 g) and magnetically stirred for $12 \mathrm{~h}$ at room temperature. The resulting solution was electrospun into nanofibers by applying electrical potential, collecting distance, flow rate and humidity of $15 \mathrm{kV}, 25 \mathrm{~cm}, 1 \mathrm{ml} / \mathrm{h}$ and 35\%, respectively. The nanofiber felt was collected by a aluminium foil for $10 \mathrm{~h}$. The as-spun PAN felt was preoxidized at $260{ }^{\circ} \mathrm{C}$ (air, $1{ }^{\circ} \mathrm{C} / \mathrm{min}, 1 \mathrm{~h}$ ) and carbonized at $1000{ }^{\circ} \mathrm{C}$, and the CNFs were obtained.

The CEs were prepared by a spray-coating technique, the method as follow: CNFs (70 mg, 100 $\mathrm{mg} 120 \mathrm{mg}$ ) were added in isopropanol $(7 \mathrm{ml}, 10 \mathrm{ml}, 12 \mathrm{ml})$ with ball-milling dispersed for $4 \mathrm{~h}$ and obtained suspension. After $\mathrm{TiO}_{2}$ (35 mg $50 \mathrm{mg}, 60 \mathrm{mg}$ ) had been doppe in suspension, the mixed solution was ultrasonicated for 30 minutes. Then the prepared mixed solution was sprayed on FTO glass and sintered in a tube furnace under $\mathrm{N}_{2}$ atmosphere at $500^{\circ} \mathrm{C}$ for $30 \mathrm{~min}$, and the CNFs CE was prepared. The CNF film thicknesses of A, B, and C are 9, 13, and $18 \mu \mathrm{m}$, respectively.

The afforded $\mathrm{TiO}_{2}$ photoanodes were further sensitized by immersing them into the YD2-o-C8 dye for $24 \mathrm{~h}$. Then the DSSC was fabricated by sandwiching redox electrolyte between dyesensitized $\mathrm{TiO}_{2}$ photoanode and FTO supported CNFs CEs. The redox electrolyte composed of 0.25 M Co (II) tris (bipyridyl) tetracyanoborate, $0.05 \mathrm{M} \mathrm{Co(III)} \mathrm{tris} \mathrm{(bipyridyl)} \mathrm{tetracyanoborate,} 0.5 \mathrm{M}$ TBP and $0.1 \mathrm{M}$ LiTFSI in acetonitrile.

\section{Characterization}

The surface features of CNFs were characterized by using a scanning electron microscopy (SEM). The cyclic voltammetry (CV) and Tafel polarization measurements were carried out in an electrochemical workstation system. The current density-voltage $(J-V)$ characteristics of the DSSCs were measured in simulated AM 1.5 illumination.

\section{Results and Discussion}

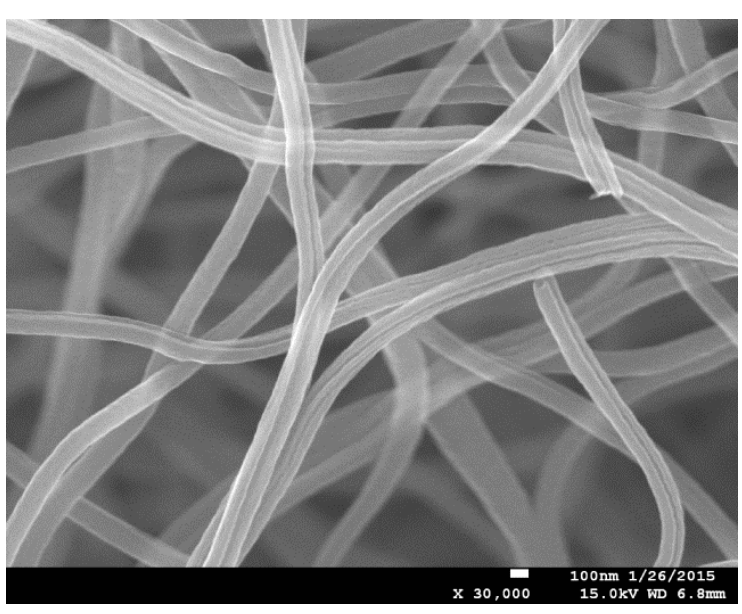

Fig. 1 SEM image of SCF

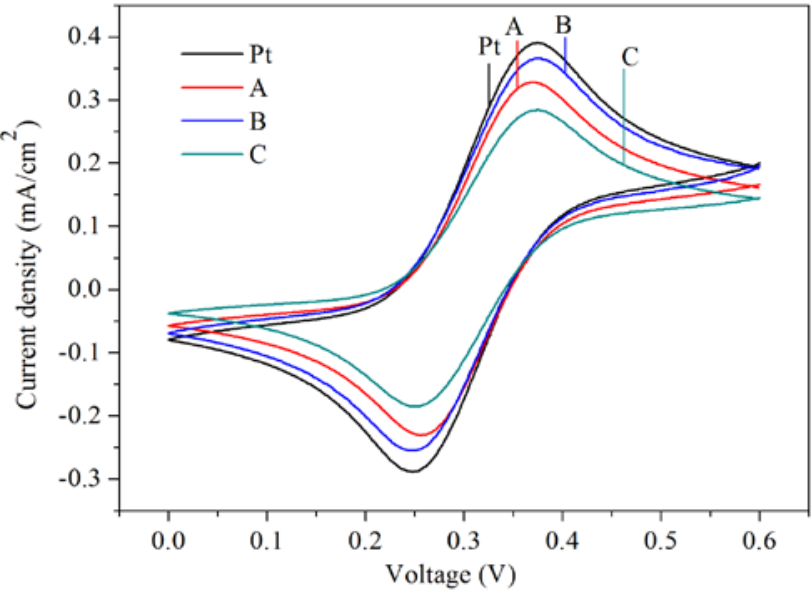

Fig. 2 CV images of four different CEs

The surface morphology of CNFs was examined by field-emission scanning electron microscope (SEM). Fig. 1 shows the SEM image of CNFs, showing that the nanofibers showed smooth surface with diameter of approximately 200-250 nm.

In the cyclic voltammogram (CV), as shown in Fig. 2, the peak positions of the CNFs CEs are similar to those of the Pt CE. The peak current densities with an order of B $>$ A $>$ C prove that the CEs could display the consistent catalytic activity in the same order. The larger cathodic peak current density of $B\left(0.365 \mathrm{~mA} / \mathrm{cm}^{2}\right)$ is in close proximity to Pt $\left(0.39 \mathrm{~mA} / \mathrm{cm}^{2}\right)$. In addition, the peak-to-peak separation $\left(\mathrm{E}_{\mathrm{pp}}\right)$ of $\mathrm{A}, \mathrm{B}, \mathrm{C}$ and Pt are extremely approximate. Overall, the CNF of film thicknesses as $13 \mu \mathrm{m}$ showed superior catalytic activity. 
Tafel polarization was carried out and showed in Fig. 3 by performing with the symmetrical cells to prove the interfacial charge-transfer capabilities at the CE/electrolyte interface. A similar slope was obtained for the B CE and Pt CE which is clearly higer than that of the A and C CEs, indicating that the catalytic activity t of B CE closes to Pt CE, and higher than A and C CEs.

Fig. 4 shows the photocurrent density-voltage (J-V) curves of the DSSCs with Pt and CNF layers of different thicknesses as CEs with detailed photovoltaic parameters listed in Table 1. The DSSC using B as the CE exhibited a high PCE of 6.07\%, reaching the photovoltaic performance of the DSSC with a Pt CE (6.2\%). The result demonstrates that CNFs show high catalytic activity in DSSC. When the CNF layer was thicker than the optimization film thicknesses of $13 \mu \mathrm{m}$, the PCE began to decrease due to the fact that too thick film may crack slightly because of CNFs film body stress.
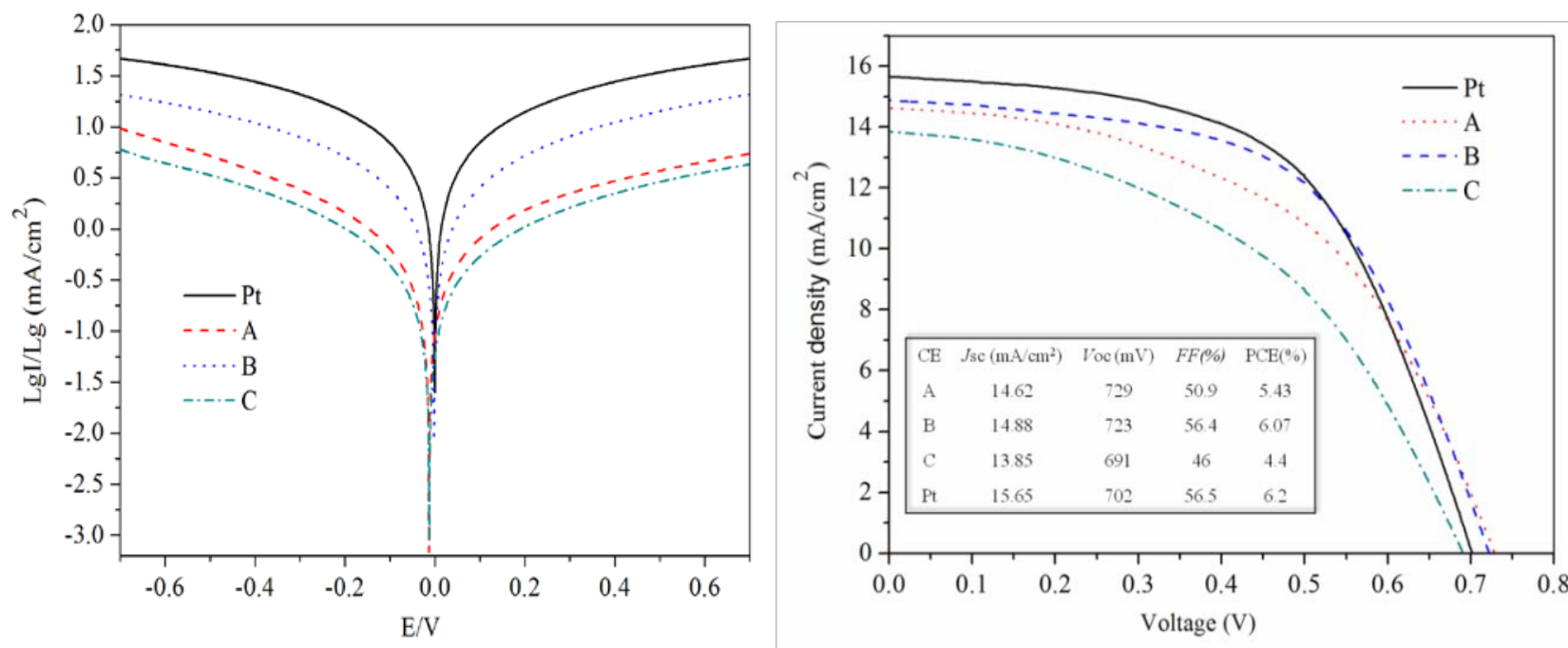

Fig. 3 Tafel curves of four different CEs

Fig 4. $J$ - $V$ curves of the DSSCs using different CEs

\section{Conclusions}

We brought in a new type cobalt electrolyte and researched the influence of the thickness of the CNF CE about the performance based on the DSSC. As a result, we found that the cell obtained a high PCE of $6.07 \%$ when the film thickness was $13 \mu \mathrm{m}$. Furthermore, this study has revealed CNF to be an efficiently catalyst that can be a substitutes for expensive Pt. CNFs exhibit remarkable performance as a CE for DSSCs with the advantages of large surface area and low cost.

\section{Acknowledgements}

We gratefully acknowledge the financial support from the following sources: National Natural Science Foundation of China (NSFC) (Grants 21201053, 51077035), Specialized Research Fund for the Doctoral Program of Higher Education (20121301120005), Fund in Hebei Province Natural Science (F2014201078, A2015201050), Youth Fund in Hebei Province Department of Education China (QN2014057), Fund in Hebei Province Applied Basic Research Project (14964306 D) and Outstanding Youth Fund of Hebei University (2015JQ02). Hebei University College Students' Innovative Entrepreneurial Training Program (201410075014, 201410075082, CYE409, CYE410), Hebei University Innovation Entrepreneurship Training Program (2015066, 2015064, 026, 201510075047), Key Project in Hebei Province Department of Education (ZD2016055), Postgraduate's Innovation Fund Project of Hebei Province ( S2016023 ), and Post-graduate’s Innovation Fund Projec of Hebei University (X2016065, X2016066). 


\section{References}

[1] B. O'Regan, M. Grätzel, Low-cost high-efficiency solar cell based on dye-sensitized colloidal $\mathrm{TiO}_{2}$ films, Nature. 353 (1991) 737-740.

[2] M. Grätzel, Photoelectrochemical cells, Nature. 414 (2001) 338-344.

[3] S. Mathew, A. Yella, P. Gao, Dye-sensitized solar cells with 13\% efficiency achieved through the molecular engineering of porphyrin sensitizers, Nature Chem. 6 (2014) 242-247.

[4] N. Huang, Y. Xie, B. Sebo, Morphology transformations in tetrabutyl titanate-acetic acid system and sub-micron/micron hierarchical $\mathrm{TiO}_{2}$ for dye-sensitized solar cells, J. Power Sources. 242 (2013) 848-854.

[5] W. R. Erwin, L. Oakes, S. Chatterjee, H.F. Zarick, Engineered porous silicon counter electrodes for high efficiency dye-sensitized solar cells, Acs Appl. Mater. Interfaces. 6 (2014) 9904-9910.

[6] G. Zhu, X. J. Wang, H. L. Li, L.K. Pan, H.C. Sun, X. J. Liu, T. Lv, Z. Sun, $\mathrm{Y}_{3} \mathrm{Al}_{5} \mathrm{O}_{12}$ :Ce phosphors as a scattering layer for high-efficiency dye-sensitized solar cells, Chem. Commun. 48 (2012) 958-960.

[7] N. Zhou, H. Lin, S.J. Lou, X. Yu, P. Guo, E. F. Manley, S. Loser, P. Hartnett, H. Huang, M. R. Wasielewski, L. X. Chen, R. P. H. Chang, A. Facchetti, T. J. Marks, Morphology-performance relationships in high-efficiency all-polymer solar cells, Adv. Energy Mater. 4 (2014)112-115.

[8] N. Zhou, X. Guo, R. P. Ortiz, S. Li, S. Zhang, R. P. H. Chang, A. Facchetti, T. J. Marks, Bithiophene imide and benzodithiophene copolymers for efficient inverted polymer solar cells, Adv. Mater. 24 (2012) 2242-2248.

[9] G. Zhu, L. K. Pan, T. Lu, T. Xu, Z. Sun, Electrophoretic deposition of reduced graphene-carbon nanotubes composite films as counter electrodes of dye-sensitized solar cells, J. Mater. Chem. 21 (2011) 14869-14875.

[10] J. Y. Lin, W. Y. Wang, Y. T. Lin, S. W. Chou, $\mathrm{Ni}_{3} \mathrm{~S}_{2} / \mathrm{Ni}-\mathrm{P}$ bilayer coated on polyimide as a Ptand TCO-free flexible counter electrode for dye-sensitized solar cells, ACS Appl. Mater. Interfaces. 6 (2014) 3357-3364.

[11] A. Kay, M. Grätzel, Low cost photovoltaic modules based on dye sensitized nanocrystalline titanium dioxide and carbon powder, Sol. Energy Mater. Sol. Cells. 44 (1996) 99-117.

[12] H. Lindström, A. Holmberg, E. Magnusson, S. E. Lindquist, L. Malmqvist, A. Hagfeld, A new method for manufacturing nanostructured electrodes on plastic substrates, Nano Lett. 1 (2001) 97100.

[13] Y. Xiao, J. Wu, G. Yue, J. Lin, M. Huang, L. Fan, Z. Lan, The surface treatment of Ti meshes for use in large-area flexible dye-sensitized solar cells, J. Power Sources. 208 (2012) 197-202.

[14] J. Wu, Y. Xiao, G. Yue, Q. Tang, J. Lin, M. Huang, Y. Huang, L. Fan, Z. Lan, S. Yin, T. Sato, A large-area light-weight dye-sensitized solar cell based on all titanium substrates with an efficiency of 6.69\% outdoors, Adv. Mater. 24 (2012) 1884-1888.

[15] T. N. Murakami, S. Ito, Q. Wang, M. K. Nazeeruddin, T. Besho, I. Cesar, P. Liska, R. Humphry-Baker, P. Comte, P. Péchy, M. Grätzel, Highly efficient dye-sensitized solar cells based on carbon black counter electrodes , J. Electrochem. Soc. 153 (2006) A2255-A2261.

[16] M. H. Al-Saleh, U. Sundararaj, A review of vapor grown carbon nanofiber/polymer conductive composites, Carbon. 47 (2009) 2-22. 